\title{
EJSBS
}

The European Journal of Social \&

Behavioural Science

ISSN: 2301.2218 (ONUINE)
OPEN ACCESS

The European Journal of Social and Behavioural Sciences

EJSBS Volume XXX, Issue III (eISSN: 2301-2218)

\section{COGNITIVE AND SOCIOCULTURAL PERSPECTIVES: APPROACHES AND IMPLICATIONS FOR LEARNING, TEACHING AND ASSESSMENT}

\author{
Jason D. Gold ${ }^{\text {* }}$ \\ ${ }^{a}$ Kobe University, Tsurukabuto Campus/Kobe, Japan
}

\begin{abstract}
The primary role of educators is to best serve and support students' learning. To this end, the epistemological beliefs they hold are immensely influential, governing (both explicitly and implicitly) educators' assumptions about how students learn, which determines the curriculum design and instructional methods utilized to support that learning. Over the years, two prominent and influential epistemological theories have developed - the cognitive perspective, which focuses on learners' mental processes, and the sociocultural perspective, which focuses on learners' participation in social practices within a particular context - with each providing their own unique contributions to the field of education. Using the example of the learning goal of students' mastery of English for passing the TOEFL, the purpose of this paper is to explore how these two perspectives view knowing and learning, and the implications of this for motivating engagement and assessing learning. By drawing on and utilizing a synthesis of the cognitive and sociocultural perspectives, educators can align their learning outcomes with the most pedagogically-appropriate approach possible, to best support overall student learning and academic success.
\end{abstract}

Keywords: Cognitive theory, sociocultural theory, learning and teaching, TOEFL, motivation, assessment

(C) 2021 Published by European Publisher. www.europeanpublisher.com

\footnotetext{
${ }^{*}$ Corresponding author.

E-mail address: Jason.gold@gold.kobe-u.ac.jp
}

doi: $10.15405 /$ ejsbs.301 
https://doi.org/10.15405/ejsbs.301

eISSN: 2301-2218 / Corresponding Author: Jason D. Gold

Selection \& Peer-review under responsibility of the Editors

\section{Introduction}

Epistemology is the branch of philosophy that concerns itself with the origins and nature of knowledge (Merriam-Webster.com, 2021). With regard to student learning, the epistemological beliefs educators hold have been shown to be an important predictor of pedagogical outcomes (Schraw \& Olafson, 2003). This is due to the fact that epistemological beliefs govern (both explicitly and implicitly) educators' approach to nearly everything they do - from their view of what "knowing" and learning entail, to their curriculum design, instructional practices, and motivational strategies, to their expectations and assessment of student learning outcomes, and to even their beliefs in the role students should play in the learning process (Soleimani, 2020).

Over the years, different epistemological beliefs have resulted in the development of numerous educational theories, many of which hold divergent assumptions and predictions about student learning. Among these, two prominent and influential theories stand out, each providing unique contributions to the field of education - the cognitive perspective, which focuses on learners' mental processes, and the sociocultural perspective, which focuses on learners' participation in social practices within a particular context (Danish \& Gresalfi, 2018). The ability to apperceive and differentiate between these epistemological frameworks is advantageous for educators, as it can enable them to better align their teaching approach to the perceived needs of their students within various different learning contexts. The purpose of this paper is thus, to explore these two perspectives and their implications on learning and teaching.

For clarity, concrete examples of each perspective will be provided using the context of a language and skills university course for English Language Learners (ELLs), the primary learning goal of which is students' sufficient mastery of English to pass the Test of English as a Foreign Language (TOEFL). In order to study abroad and attend university in an Englishspeaking country, ELLs often first need to demonstrate a certain aptitude level in their language ability, often ascertained via this globally-recognized standardized proficiency test. The TOEFL has four sections (Reading, Listening, Speaking, and Writing); each consists of various tasks meant to utilize and measure students' academic and English language skills in a way similar to that of English-speaking university classrooms, to both prepare students for such an experience and to provide proof to the study abroad university of the student's English proficiency (ETS, 2020). Scoring well on the the TOEFL is of great importance to students because it can determine their future academic, professional, and life trajectory. As a result, it is worthwhile for educators to be knowledgeable of the pedagogical affordances and constraints the cognitive and sociocultural perspectives provide to best support their students' 
https://doi.org/10.15405/ejsbs.301

eISSN: 2301-2218 / Corresponding Author: Jason D. Gold

Selection \& Peer-review under responsibility of the Editors

success by utilizing the most appropriate curriculum design, motivation strategies, and assessment method.

The first section of this paper will consider what "knowing" entails in each perspective and how these assumptions define what it means to learn. The second section will then explore the implications of each perspective on how educators can motivate learner engagement and assess student learning.

\section{Cognitive vs. Sociocultural Perspectives of Knowing and Learning}

Learning is a highly complex and dynamic process that differs in people depending on how it occurs. At the individual level, it involves different brain processes along with the coordination of multiple systems and their responses to changes in one's external and internal environments. This ultimately result in changes to the biology of the brain. Yet, learning also is greatly determined at the social level, by the culture, contexts and people being interacted with when the learning occurs (National Academies of Sciences, Engineering, and Medicine, 2018). For example, in The Handbook of Education and Human Development, Case (1996) explains that "views on educational aims and methods diverge quite widely," and cites as a reason for this divergence the fact that "no general agreement exists on the nature of knowledge itself" (p. 75). The result of this divergence and the lack of agreement has been an epistemological debate that has been going on for decades (see Danish \& Gresalfi, 2018) between two prominent frameworks: the cognitive perspective and the sociocultural perspective.

Cognitive theories refer to theories that pertain to the mind, particularly the mental processes involved in the development and organization of general and/or specific cognitive structures. These allow us to understand concepts and theories in different subject matter domains, as well as undertake general cognitive processes across domains such as reasoning, planning, metacognition, and problem solving. In contrast, sociocultural refers to theories which "at their core, consider human activity to be inseparable from the contexts, practices, and histories in which activity takes place" (Danish \& Gresalfi, 2018, p. 36). These theories focus not just on individuals, but on the contexts in which individuals act together with others. Recognizing the differences between these perspectives and knowing which approach(es) to 
https://doi.org/10.15405/ejsbs.301

eISSN: 2301-2218 / Corresponding Author: Jason D. Gold

Selection \& Peer-review under responsibility of the Editors

use, when, and for what purposes is pertinent for educators to best teach and serve their students.

\subsection{Knowing in the cognitive perspective}

The cognitive perspective focuses on the mental processes and internal constructs of the individual learner. In this paradigm knowledge comes from the contemplation of ideas and the representation of that information within the individual mind, as well as the manipulation, transformation, and retrieval of those representations (Danish \& Gresalfi, 2018). Sfard (1998) succinctly summarizes this process using the metaphor of 'learning as acquisition,' whereby our mental constructs are created from basic units of knowledge akin to material goods that are accumulated, refined, and combined in our minds to create our higher-level structures. Over time higher-level structures are built within one's mind, which are used to assimilate and/or accommodate new knowledge. The origin of "knowing" is thus one's individual knowledge of the world, with intelligence being a result of one's capability to create and modify increasingly complex conceptual mental structures, to be applied to future contexts (Danish \& Gresalfi, 2018).

Applying this perspective to the focal example of this study, knowing for ELLs pertains to the existence of various internal mental constructs of information and skills that are needed to pass the TOEFL. This begins with the current understanding constructs for "knowing" that they possess. (e.g., basic English rules of grammar; vocabulary and word parts; pronunciation). Once each learner's level of knowing is established, learners need to continually accumulate, refine, and combine new language knowledge acquisition in their minds to create higher schemata, or mental conceptual frameworks (Brown et al., 2014). This also pertains to knowing the TOEFL itself - test comoposition, what each component entails regarding English language ability, etc. Once students have acquired this knowledge within their long-term memory (internal constructs), they can then retrieve it at a future date to aid them in further learning and eventually, their undertaking of the TOEFL.

\subsubsection{Expertise in the cognitive perspective}

In How People Learn (National Research Council, 2000), a wealth of research is summarized regarding how experts differ from novices, and several key principles of experts' knowledge are outlined. Compared to novices, experts are better able to notice features and meaningful patterns of information and organize the breadth of their acquired content knowledge in meaningful ways that reflect a deeper comprehension of core concepts. Further, they can "conditionalize" their knowing based on the given context and retrieve the important 
https://doi.org/10.15405/ejsbs.301

eISSN: 2301-2218 / Corresponding Author: Jason D. Gold

Selection \& Peer-review under responsibility of the Editors

aspects of knowledge fluently, and are flexible in their approach to new learning experiences (p. 31). From this, it becomes clear that experts are not simply better problem-solvers or have more content knowledge at their disposal than novices, but rather have incorporated their breadth of knowledge into well-organized and interrelated mental schema, which they can draw upon and apply fluently and flexibly to a context.

Consdering the cognitive perspective within a practical lens, how learners studying for the TOEFL operationalize their knowing is a key consideration. With regard to students' mastery of English for the TOEFL, consider a given reading comprehension task; noviceconstructed mental schema will initially consist of superficial surface-level features focused on individual language aspects, such as knowledge of how to decipher, read, and recall the meaning of individual words in isolation. In contrast, higher-level students and experts have acquired a great deal more knowledge of the features of the English language (e.g., grammar rules, vocabulary meanings, sentence structure, etc.) and are thus able to automatically chunk words or skim sentences in order to read faster with more comprehension, freeing up their precious mental resources (Brown et al., 2014) to focus on completing the specific higherlevel TOEFL tasks, such as finding the main ideas, inferring relationships, synthesizing meaning, etc. Lacking a hierarchical, highly organized schema of the English language, novices are unable to divert their mental resources effectively, so the majority of their attention remains devoted to surface level comprehension (LaBerge \& Samuels, 1974).

This difference between novices and experts also holds true with regard to the TOEFL test structure itself and related test-taking strategies. Students taking the test for the first time need to focus on everything (e.g., directions, sections, types of questions, time limit, etc.) due to their lack of knowledge. However, those learners with more expertise already know what is required for each component so they are able to conditionalize their test-taking skills to each task more fluently. For example, on the prior reading comprehension task, novices tend to read each question in order of appearance and then try to read the entire passage to find the answer. Contrastingly, experts know this section requires the skills of quickly scanning the questions for the easiest ones first (e.g., facts, vocabulary meaning, etc.) and then quickly scanning the text for the answer to that specific question. The experts with more experience have built a schema in their minds, including what questions or tasks entail, what skills and how to utilize those while, at the same time, attending to the English language features. Thus, not just the 
https://doi.org/10.15405/ejsbs.301

eISSN: 2301-2218 / Corresponding Author: Jason D. Gold

Selection \& Peer-review under responsibility of the Editors

amount of knowledge but also the quality of knowing differs greatly between novices and experts.

\subsection{Knowing in the sociocultural perspective}

In contrast to the cognitive view, the sociocultural perspective holds that "the origins of knowledge and the processes of engaging knowledge stem from the cultural and historical practices in which the individual is immersed," and thus, "how one comes to know something is inseparable from what one ultimately comes to know" (Danish \& Gresalfi, 2018, p. 36). The individual and the current learning context (with its own unique and specific culture, practices, histories, etc.) are not only inseparable, but two sides of the same coin, with both influencing cognition and knowing (Case, 1996). In this view, knowledge is not acquired and stored in mental constructs but rather is interwoven with culture and context, and consists of knowing the practices, affordances, and constraints of the social activities within the community of practice and learning to be a successful participant. The origin of "knowing" and intelligence is thus, dependent on one's sociocultural interaction with the world (Greeno et al., 1996).

In the context of this paper's example learning goal, students gradually come to know the specific language and socio-histories involved in knowing the English language to pass the TOEFL. This would consist of the various prioritized discourses found in the context of Western English-speaking university settings that the TOEFL is assessing, focusing on "academic" understandings and applications of reading (e.g., textbook passages in various disciplines), listening (e.g., lectures), writing (e.g., critical essays), and speaking (e.g., argumentation) that would enable the learner to fluently participate in a university setting. Through participation, students gain access to the social group (i.e., community) of L2 English-language learners, gradually becoming active participants and in the process cocreating knowing through discourse with the social group and the tools available (Wenger, 1999). “The target for many second language learners is not just 'to speak another language,' but to become part of the social and cultural environment in which the language is used. This entails frequent and rich participation in the second-language life worlds into which the learner 'bricolages' his or her way" (Wagner, 2015, p. 95-96). In this view, how students socially come to know the TOEFL is inseparable from what students ultimately end up knowing.

\subsubsection{Expertise in the sociocultural perspective}

A bridge from the cognitive view of solely internal mental structures being responsible for the novice-expert distinction towards the sociocultural perspective's emphasis of the import of social contexts and environments is provided by situated cognition theory, which 
https://doi.org/10.15405/ejsbs.301

eISSN: 2301-2218 / Corresponding Author: Jason D. Gold

Selection \& Peer-review under responsibility of the Editors

states that knowledge lies not only within the individual, but in the individual's social and physical environment (Hutchins, 1995). Theories of situated cognition argue that "knowledge entails lived practices, not just accumulated information, and the processes of learning are negotiated with people in what they do, through experiences in the social practices associated with particular activities" (Johnson, 2006, p. 237).

In the sociocultural view, expertise of the English language to pass the TOEFL is coconstructed by students in their environment. Expertise is tacit knowing of the language and culture needed to participate in the discourse of English with their peers as well as those outside of the learning environment. Knowing the English language doesn't just involve memorized features or structures, but also involves and is influenced by participation with other actors, in a certain environment, within a certain set of sociocultural histories; where one is, who one is talking to, in what context, and for what purpose all influence one's knowing and usage of the language in that particular context. Thus, expertise consists of being able to navigate and fluently know both the explicit and implicit nuances, cues, and meaning-making involved, which allows for participation and membership within the English-speaking community.

\subsection{Learning in the cognitive perspective}

While knowing in the cognitive perspective is seen as the acquisition and accumulation of knowledge, learning is viewed as the meaningful organization of this acquired knowledge around important ideas or concepts, ultimately leading to greater conceptual understanding. Acquired knowledge is gradually refined, combined, and synthesized with existing internal structures to form ever richer cognitive structures (Sfard, 1996), with learning consisting of the encoding to one's long-term memory key aspects of the concept to be learned (e.g., terminology, rules, models, etc.) for future retrieval via the creation of internal mental constructs. To accomplish this, learners may use various senses (perceptual learning) or physically engage with objects (motor learning), or watch expert others (observational learning), but the end result is individual accommodation and/or assimilation of knowledge bits internally that the learner now "owns" (Metcalfe, 2013). However, meaningful learning is not just the mechanical accumulation of facts but also depends greatly on what one already knows by assimilating or accommodating new ideas to pre-existing ones, ultimately reshaping and reconstructing the knowledge itself (Fosnot, 1989). Thus, a major factor affecting one's learning is the level and adequacy of the internal models one constructs.

In this cognitive view, learning English to pass the TOEFL consists of encoding the vast amount of necessary knowledge of the English language as well as the metacognitive strategies and test-taking skills required to successfully answer the various tasks of the four 
https://doi.org/10.15405/ejsbs.301

eISSN: 2301-2218 / Corresponding Author: Jason D. Gold

Selection \& Peer-review under responsibility of the Editors

sections of the test. This knowledge of English would start off basic, but would gradually develop further as the learner continually refined, combined, and synthesized new knowledge and experiences, accommodating or assimilating it with existing internal structures to create ever richer cognitive structures of English. This recursive cycle of learning could occur both through one's active learning practices (e.g., studying a textbook, doing test practice questions, etc.) or through the observation of more experienced others (e.g., listening to the teacher, watching movies in English, etc.), as long as meaningful encoding occurred which the learner can retrieve and utilize in the future. After enough time, effort, meaningful experience, and successful encoding, the learner will have created a highly-developed cognitive framework consisting of vast amounts of both English language and TOEFL test knowledge and experience that can be applied to the successful undertaking of the test.

\subsection{Learning in the sociocultural perspective}

Decades of educational research (NAS, 2018) have come to clearly illustrate the integral interrelatedness of culture to learning, particularly that individuals learn in "culturally defined ways in culturally defined contexts" (p. 2). This has resulted in a key theoretical shift in education research, in which the learner can no longer be viewed or understood as separate from his/her environment. Instead, all learning is seen as a social process that is shaped and fused by the cultural processes present within the learning environment itself. Culture is a living system, and influences not only what people learn but also how they learn it. This influences cognitive processes that shape learning, such as perception and memory, altering how students ultimately come to understand and see the world. This even extends to what is desirable to learn in the first place, which can differ greatly across cultures, especially between home cultures and hegemonic academic settings where different cultural norms, values, and goals exist and may conflict. Therefore, a full understanding of how one learns cannot occur without considering cultural processes, since they can either promote or hamper learning, depending on the context and type(s) of learning valued.

The purpose of human language is ultimately social in nature, and thus, in the sociocultural view, social interactions play a vital role in the learning of English for the TOEFL and serve as the main channel through which this learning happens. Vygotsky (1978) explained that language learners actively engage in social interactions with more experienced members through a kind of regulated interaction called the Zone of Proximal Development (ZPD), where the transition from other regulation (inter-mental activity) to self-regulation (intra-mental activity) happens. A language learner has two developmental levels - their individual level based on their ability without help from others, and their potential level based on their 
https://doi.org/10.15405/ejsbs.301

eISSN: 2301-2218 / Corresponding Author: Jason D. Gold

Selection \& Peer-review under responsibility of the Editors

capabilities when engaging with more knowledgeable others from the same culture and receiving assistance from them. Through social interactions, more experienced learners are able to guide and aid less experienced learners in the knowledge and behaviors necessary to participate, with gaps in learners' knowing filled through the observation of members' behaviors and active participation in the shared context. From participating in these social interactions, microgenetic development occurs within the language learner's ZPD, gradually leading to a reduced need for scaffolding and other regulation by the expert, and culminating in individual language expertise - a "knowing" of how to fluently use and engage in culturallyappropriate discourse with others (Dongyu et al., 2013).

Thus, learning is "a joint accomplishment between the individual and the rich context in which she is participating" (Danish \& Gresalfi, 2018, p. 36), with the approach to learning being embedded in the practices of communities. This means learning is unique and distinct for every individual, due to the varying cultural influences one encounters throughout one's life. From social interactions with their peers and teachers, English language learners are gradually able to lessen their need for support from their teacher and classmates and eventually (on their own) come to be able to successfully pass the TOEFL.

\section{Implications for Education}

As the previous sections on knowing and learning have illustrated, which epistemological stance(s) educators take will ultimately influences their view towards classroom teaching - the activities they plan, the teaching styles they utilize, and their expectations on what learning "looks" like. Teachers have immense influence on what students learn and how they learn it; thus, it is important that they consciously ensure they are aligning their epistemological beliefs with their teaching pedagogy in ways that best support their students' learning.

However, while the assumptions about knowing and learning are epistemologically tightly linked, the relationship between those assumptions to the practices of motivating engagement and assessing learning may be less evident. For example, practitioners frequently blend approaches from both in order to come up with novel and equitable solutions to modern educational and societal challenges. Though the two perspectives may differ in their overall epistemological practices, they do share a common goal - to cultivate a learning environment where all learners, regardless of race or age or gender are able to learn and succeed in their academic endeavors. The rest of this paper will discuss how educators can go about motivating engagement and assessing learning in their students from the cognitive and the sociocultural 
https://doi.org/10.15405/ejsbs.301

eISSN: 2301-2218 / Corresponding Author: Jason D. Gold

Selection \& Peer-review under responsibility of the Editors

perspectives, continuing to use the learning goal of mastering English to pass the TOEFL as an illustrative example.

\section{Cognitive vs. Sociocultural Approaches to Education}

Within the cognitive perspective, educators are primarily concerned with teaching models of cognition that have been observed in experts within specific and/or general content area domains through sequences for conceptual development. The learning environment is designed to facilitate students' construction of conceptual understanding of generalities and unifying principles, as well as their ability to solve novel problems using expert models. In this view, there are various theories to explain learner motivation and engagement, though in general these are viewed as internal, individual states of the learner, and tied to their selfefficacy in interacting with and solving problems. Cognitive assessment approaches focus on the individual's knowledge, learning, and transfer of specific and/or general domain principles through extended performance, by employing methods and strategies that are relevant and meaningful within that domain (Danish \& Gresalfi, 2018).

Within the sociocultural perspective, educators consider the specific learning context as well as the learners' culture(s) relevant, if not paramount, to each aspect of the educational process. In such an approach, the teacher embraces the racial, ethnic, linguistic, and cultural diversity and assets their students bring to the classroom, and is able to draw out and utilize this together with the academic content of the classroom during learning experiences. Both the teacher and students recognize, learn about, and respect one another's cultures and beliefs. This is accomplished by the teacher drawing on past student learning and experiences and connecting their culture to the academic learning content and building on it, and engaging students in critical reflections about their lives and society.

\subsection{Cognitive Approaches to Motivating Engagement}

Students' motivation and engagement in academics are considered crucial to successful learning and have been linked to positive learning outcomes both in and out of school, as well as key to addressing educational issues such as low academic achievement and increasing dropout rates (Heddy \& Sinatra, 2013; Sinatra et al., 2015). However, it is first necessary for educators to understand what they mean by the terms 'motivation' and 'engagement,' since what each entails and how to design instruction that positively supports these can vary greatly. Such variations are caused by the epistemological stance of the educator, which influence their view on the nature of learning, and by the practices of the specific field of discipline, which 
https://doi.org/10.15405/ejsbs.301

eISSN: 2301-2218 / Corresponding Author: Jason D. Gold

Selection \& Peer-review under responsibility of the Editors

influences and will invariably lead to different questions, methods, aims, and evidence regarding motivation and engagement.

To reiterate, the cognitive perspective posits that changes in conceptual understanding, strategies, and skills are located mainly within the mind of the individual. Therefore, most cognitive approaches to understanding motivation and engagement deal separately with the person and the context, tending to focus mainly on factors within the learner. A wide range of studies (see Dweck et al., 2014) have come to show that psychological factors such as students' mindsets about their intelligence and abilities, their academic habits, and their feelings about school and learning in general can greatly influence their academic performance. The cognitive approach seeks to create generalizable models that can explain what these psychological factors are, and from this, uncover what motivates learners, how, and why.

Student engagement can be viewed from various different (domain-general) dimensions, such as behavioral, emotional, and cognitive. Behavioral engagement consists of students' involvement in their own academic learning process, and can include their positive academic behavior, participation in academic tasks, and involvement in school-related activities (Heddy et al., 2014). This dimension of engagement takes the form of displays of student effort and persistence, behavioral aspects of attention (e.g., eye contact, active listening), and self-regulation of academic behavior. Emotional engagement is students' emotional reactions (positive or negative) to the academic subjects they are studying, often based on their perceptions of both current and future academic value, as well as personal interest. While negative emotions may at times aid in facilitating motivation and engagement, research has shown generally positive emotions are better at doing so (Heddy \& Sinatra, 2013). Cognitive engagement is generally likened to students' psychological investment with their learning, such as taking the extra time and energy to choose cognitively-challenging tasks and expend effort to fully understand the learning. Such students tend to exhibit a higher level of self-regulation and self-efficacy, as well as set mastery goals which engage them in deeper learning, all of which have been shown in research to lead to positive academic achievement (Greene, 2015).

In the example of students studying English for the TOEFL, the teacher would consider which domain-general psychological research-backed strategies they want to utilize to encourage and foster engagement in the learning goal. These could consist of selfdetermination theory (Ryan \& Deci, 2000), focusing on fostering students' autonomy, competence, and relatedness associated with learning English and being an English-speaker, expectancy-value theory (Wigfield \& Eccles, 2000), focusing on fostering students' perceived attainment value and expectations related to the importance that English fluency and a high 
https://doi.org/10.15405/ejsbs.301

eISSN: 2301-2218 / Corresponding Author: Jason D. Gold

Selection \& Peer-review under responsibility of the Editors

TOEFL score will have on their future lives, learner mindset theory (Dweck, 2012) focusing on reframing students' view of intelligence/ability, effort, and setbacks towards language learning and test results in a growth (vs. fixed) way, etc. Taken a step further, instructors also have the option to consider domain-specific factors of motivation and utilize second language acquisition (SLA) theories to further enhance students' engagement in their learning of English for the TOEFL. This level of integration requires teachers to consider the blending of theories from different scopes of learning and teaching.

\subsection{Sociocultural Approaches to Motivating Engagement}

Critiques of cognitive motivation models stem from their incomplete explanations of variance in outcomes between individuals, which suggests that factors are missing which need to be accounted for (Vansteenkiste et al., 2014). This requires a more complex and holistic approach to better understanding individuals' motivation and engagement that considers not just internal factors, but external variables as well. Thus, in contrast to cognitive approaches where context is either ignored or isolated from motivational variables, sociocultural approaches to motivating engagement take a situative approach (Sinatra et al., 2015), viewing the learning context as inseparable from the learner. In this view, educators consider not just the unique characteristics of each individual, but also the unique characteristics of the classroom, school, community, or culture within which the learner is operating. Educators also need to consider and evalauate the affordances and constraints available and to take into account their overall influences, with motivation being attributed to and distributed across both people and contexts (Nolen et al., 2015).

In this situative view, a learner's identity (or identities) within each particular context is a vital and inseparable factor to fully understanding that learner's motivation (or amotivation) and engagement (or disengagement) in that learning context. This definition of identity consists of both one's self-understandings and relatedness to the learning content/context, as well as the understandings assigned to them through one's socio-culturalhistoric position (Holland et al., 2001). Content and practices that learners find valuable and meaningful (and which thus resonate with their learner identity) can motivate engagement. Motivation can also stem from messages regarding correct normative behavior from the social context and those within it that they respect (which links to a desired learner identity). As learners participate in social activities they negotiate and construct their identity; depending on the affordances and constraints available to them that support (or prevent) membership in 
https://doi.org/10.15405/ejsbs.301

eISSN: 2301-2218 / Corresponding Author: Jason D. Gold

Selection \& Peer-review under responsibility of the Editors

the learning community, their motivation and engagement will thus be either enhanced or hindered.

Regarding the example of students' mastery of English for the TOEFL, to better motivate and engage the class towards this goal, the instructor should utilize situative learning approaches that take into account the unique sociocultural experiences and perspective of each individual learner. This approach coincides with the SLA concept of investment, which pertains to learners' commitment to learn a language based on their hopes for the future and their imagined identities. In this view, “if learners 'invest' in the target language, they do so with the understanding that they will acquire a wider range of symbolic resources (language, education, friendship) and material resources (capital goods, real estate, money), which will in turn increase the value of their cultural capital and social power" (Norton, 2013, p. 6). This in turn provides for a wider range of identity positions and increased engagement in learning (to attain the desired identity position). This has important implications for pedagogy, since learners may be motivated to learn, but if they have little investment in the practices of a given classroom or community, it can lead to disengagement and poor learning outcomes. Instead of viewing quiet or disengaged students as "unmotivated," it is more productive for educators to ascertain to what extent students are invested in the language and literacy practices of the classroom (Norton, 2016).

Pertaining to the goal of students' mastery of English for the TOEFL, whether the course instructor focuses on getting students invested in their learning can have repercussions on their motivation and engagement. If the instructor privileges fluent speaking or writing and whether students' get the correct answers on practice activities and tests, this will inevitably obstruct access to the identity position of "good student" and "English-speaker" for some learners who are still struggling with their learning of English. After time and enough failures these students may feel this identity is unattainable to them and withdraw from participation in the class (and perhaps the identity of English speaker altogether). Alternatively, the educator can focus the class towards self-improvement and practical use of English in their future (e.g., to study abroad, to watch movies without subtitles, or to make English friends). With that focus, the instructor can foster investment in English as an invaluable tool for their future and incorporate various mediators and collaborative learning. This type of practical model creates a greater likelihood that students will invest in learning English (i.e., be "motivated") and take up the identity of English speaker. 
https://doi.org/10.15405/ejsbs.301

eISSN: 2301-2218 / Corresponding Author: Jason D. Gold

Selection \& Peer-review under responsibility of the Editors

\section{Assessing Learning}

Educational assessment seeks to determine how well students are learning. If done properly, it provides important feedback to students and educators, as well as to other concerned parties such as parents, policy makers, and the public about the effectiveness of educational services (National Research Council, 2000). Within the classroom context, the goal of assessment should be "to educate and improve student performance, not merely to audit it" (Wiggins, 1998, p.7). Thus, each assessment situation should reveal to both educators and students useful and important information that can be utilized to improve future learning.

The authenticity of an assessment in a domain depends on how well it actually carries out its purpose of illustrating students' knowing and learning in that domain (Greeno et al., 1996). According to the National Research Council (2000), underlying all assessments is an "assessment triangle," consisting of three foundational elements: cognition, observation, and interpretation. Within this assessement triangle, cognition refers to the educator's theory pertaining to students' knowledge representations and competency development in a domain, necessitating which which knowledge and skills are important (and thus should be measured) for the task at hand. Observations relate to the assessment tasks that demonstrate students' knowledge and skill in important domain areas. These need to be designed carefully in order to align with the cognitive model of learning, to elicit the knowledge and cognitive processes deemed most important for competency in the domain. Interpretation refers to the criteria and assumptions used to evaluate and construe students' collected responses in observation about the knowledge and skills being assessed, based on the chosen cognitive model of learning. Therefore, for an assessment to be considered "good" these three elements of the assessment triangle must all be aligned - explicitly connected and designed as a coordinated wholeotherwise the meaningfulness of the inferences drawn from the assessment task will likely be inaccurate and unreliable (Pellegrino et al., 2001).

\subsection{Cognitive Approaches to Assessing Learning}

Proponents of the cognitive perspective assume that to assess students' learning it is necessary to go beyond the focus of component skills and discrete bits of knowledge and actually observe students in complex domain-appropriate activities, employing methods and strategies that are relevant and meaningful in solving problems within that domain (Greeno, 1996). In this view, assessments should "evaluate what schemas an individual has and under what circumstances he or she regards the information as relevant. This evaluation should include how a person organizes acquired information, encompassing strategies for problem 
https://doi.org/10.15405/ejsbs.301

eISSN: 2301-2218 / Corresponding Author: Jason D. Gold

Selection \& Peer-review under responsibility of the Editors

solving" (National Research Council, 2000, p. 3). Assessment is thus seen as students' ability to show what they know, how they know it, and how they should apply such knowledge and skills to answering questions within the domain. This approach to assessment can also foster better curriculum design, with educators creating tasks that focus on promoting conceptual development of key elements and processes relevant and needed in the domain. This enables educators to better ascertain students' conceptual understanding instead of just what individual bits of knowledge they have memorized. From this, educators can provide more targeted feedback regarding certain conceptual schemata or modes of reasoning students may need to work on and develop further.

Regarding this paper's example, the TOEFL's design consists of many cognitive assessment features. Its main function is to determine if students have the requisite English necessary to study abroad and succeed in academic university classes taught in English. The tasks within the four sections of the TOEFL are meant to simulate the various tasks students will be expected to be proficient in, and assess their ability to communicate and reason using these requisite skills in academic settings. For example, the listening passages of the TOEFL consist of excerpts of academic lectures on a wide-range of topics, which students need to take notes on to correctly answer subsequent questions related to the lecture. However, these questions do not focus on testing isolated vocabulary or grammar components but instead consist of various question types meant to ascertain the cognitive and metacognitive skills university students are expected to have attained. These encompass skills such as ascertaining the main idea, noting which details are important, pragmatic understandings of the passage function as well as the speaker's stance, and understanding the organization and relationships of the content. The other three sections of the TOEFL are designed similarly. By observing their students engaging in practice problems within these domain-relevant tasks using the requisite methods and strategies to solve them successfully, educators can accurately assess their overall English proficiency within both the future goal context of the academic English university classroom and the TOEFL itself.

\subsection{Sociocultural Approaches to Assessing Learning}

In contrast to the cognitive approach, proponents of the sociocultural perspective believe that knowledge is always situated within the specific socio-cultural contexts that people typically utilize such knowledge in (via participation and discourse). Thus, assessment must be as well, as it is unlikely that students' performance on context-removed assessments can accurately reflect how they would actually perform in real-world situations. This sociocultural perspective on assessment emphasizes the actual functions of assessment, rather 
https://doi.org/10.15405/ejsbs.301

eISSN: 2301-2218 / Corresponding Author: Jason D. Gold

Selection \& Peer-review under responsibility of the Editors

than just their intended purposes. An important factor is that how well students do on a given assessment is often influenced by how well they are able to participate in that particular form of practice. The style of the test, the types of questions being asked, the language being used, the implicit requisite socio-cultural-historic background knowledge, and other varying factors all can lead to some students being better prepared or able to engage more effectively in that particular assessment. This demonstrates that a context-removed approach to assessment is unable to accurately gauge with confidence students' actual knowledge and skills on a consistent basis.

Another distinct feature of the sociocultural approach to assessment is advocating students' participation in the process of assessment construction when possible. This leads to assessment becoming a collaborative endeavor in which students have some autonomy, resulting in better comprehension of the criterion that will be used to judge the quality of their work (Gipps, 2002). This promotes more effective learning and provides "opportunities for them to develop their own standards, their abilities for intellectual judgement, and their sense of personal responsibility for their individual work" (Greeno, 1996, p. 39). Assessment results and accompanying feedback on their learning and development are meant to increase students' engagement in the learning process and bolster their sense of competence as a participant in the community of practice.

Returning to the focal example of this paper, while educators teaching TOEFL courses have no say on the style of the test itself, they can incorporate a sociocultural approach to how they go about assessing their own class. This approach would require student participation and discourse in the actual practices of a university English-speaking classroom context and to have students gain first-hand experience utilizing the kind of knowledge that both the TOEFL assesses and that they will need when they study abroad. This form of assessment would stem from not just their individual homework assignments or practice test scores, but also from how well students engage in communicative practices appropriate to the TOEFL/academic Englishspeaking classroom. This could consist of small group or class discourse of TOEFL speaking and writing tasks or listening and reading passages. In these scenarios, students (in English) discuss not just the contents and answers to the tasks, but also the language used to participate in these discussions, as well as their metacognitive skills and strategies regarding how they think about and go about answering such questions.

Regarding the kinds of assessments utilized, the instructor can collaboratively design them together with their students by discussing with them at the start of the semester what kinds of assignments would most benefit their own goals and reasons for seeking mastery of English for the TOEFL. Further, the instructor can discuss what kind of grading criteria should 
https://doi.org/10.15405/ejsbs.301

eISSN: 2301-2218 / Corresponding Author: Jason D. Gold

Selection \& Peer-review under responsibility of the Editors

be used. This would give students choice in the kinds of activities they undertake throughout the semester to demonstrate their understanding of English and the skills needed for the TOEFL. Implementing a system like this can help foster more student autonomy and facilitate a sense of personal responsibility, ultimately leading to an increase in students' engagement in the learning process as they strive to gain competence as a participant of the English-speaking community of practice. This requires the students to have a particular acumen in metcognitive skills and shows the importance of these skills in the sociocultural perspective with respect to assessment of learning.

\section{Conclusion: The Value of Synthesizing Insights}

This paper has demonstrated the epistemological beliefs one an instructor holds drives assumptions about what knowledge is and how students learn. This ultimately has the potential to determine the curriculum design and instructional methods utilized to support that learning. Both the cognitive and sociocultural perspectives can offer unique and valuable insights, as was shown through the example of the learning goal of students' mastery of English for passing the TOEFL. Each perspective offers something that the other,on its own, simply cannot provide.

The primary purpose of teaching is to best serve and support students' learning; thus, educators should strive to consider aspects of both epistemological frameworks to best fit their specific teaching content and context. Since "no two students have the same needs and no two teachers arrive at their best performance in the same way, theoretical exclusivity and didactic single-mindedness can be trusted to make even the best educational ideas fail" (Sfard, 1998, p. 11). Drawing on and utilizing a synthesis of the cognitive and sociocultural perspectives allow educators to become more adept at aligning their learning outcomes with the most pedagogically-appropriate approach to best aid their students in their academic learning and success.

\section{Acknowledgements}

The author(s) declare that there is no conflict of interest.

\section{References}

Brown, P. C., Roediger III, H. L., \& McDaniel, M. A. (2014). Make it stick. Harvard University Press.

Case, R. (1996). Changing views of knowledge and their impact on educational research and practice. In D. R. Olson \& N. Torrance (Eds.), The handbook of education and human 
development: New models of learning, teaching and schooling (pp. 75-99). Blackwell Publishing.

Danish, J. A., \& Gresalfi, M. (2018). Cognitive and sociocultural perspectives on learning: Tensions and synergy in the learning sciences. In F. Fischer, C. E. Hmelo-Silver, S. R. Goldman \& P. Reimann (Eds.), International handbook of the learning sciences (pp. 34-43). Routledge. https://doi.org/10.4324/9781315617572-4

Dongyu, Z., Fanyu, B., \& Wanyi, D. (2013). Sociocultural theory applied to second language learning: Collaborative learning with reference to the Chinese context. International education studies, 6(9), 165-174. https://doi.org/10.5539/ies.v6n9p165

Dweck, C. (2012). Mindset: Changing the way you think to fulfil your potential. Hachette.

Dweck, C. S., Walton, G. M., \& Cohen, G. L. (2014). Academic tenacity: Mindsets and skills that promote long-term learning. Bill \& Melinda Gates Foundation.

Epistemology. (n.d.) In Merriam-Webster's collegiate dictionary. https://www.merriamwebster.com/dictionary/epistemology

ETS. (2020). About the TOEFL iBT® Test. https://www.ets.org/toefl/test-takers/ibt/about

Fosnot, C. T. (1989). Enquiring teachers, enquiring learners: A constructivist approach for teaching. Teachers College Press.

Gipps, C. (2002). Sociocultural perspectives on assessment. In G. Wells, \& G. Claxton (Eds.), Learning for life in the 21st century, (pp. 73-83). Blackwell publishers. https://doi.org/10.1002/9780470753545.ch6

Greene, B. A. (2015). Measuring cognitive engagement with self-report scales: Reflections from over 20 years of research. Educational Psychologist, 50(1), 14-30. https://psycnet.apa.org/doi/10.1080/00461520.2014.989230

Greeno, J. G., Collins, A. M., \& Resnick, L. B. (1996). Cognition and learning. In D. Berliner \& R. Calfee (Eds.), Handbook of educational psychology (pp. 15-46). Macmillan

Heddy, B. C., \& Sinatra, G. M. (2013). Transforming misconceptions: Using transformative experience to promote positive affect and conceptual change in students learning about biological evolution. Science Education, 97(5), 723-744. https://doi.org/10.1002/sce.21072

Heddy, B. C., Sinatra, G. M., Seli, H., \& Mukhopadhyay, A. (2014, April). Transformative experience as a facilitator of interest development and transfer in a college success course for at-risk students. Paper presented at the American Educational Research Association, Philadelphia, PA.

Holland, D. C., Lachicotte Jr, W. S., Skinner, D., \& Cain, C. (2001). Identity and agency in cultural worlds. Harvard University Press.

Hutchins, E. (1995). How a cockpit remembers its speeds. Cognitive Science, 19(3), 265-288. https://doi.org/10.1016/0364-0213(95)90020-9

Johnson, K. E. (2006). The sociocultural turn and its challenges for second language teacher education. TESOL Quarterly, 4O(1), 235-257. https://doi.org/10.2307/40264518

LaBerge, D., \& Samuels, S. J. (1974). Toward a theory of automatic information processing in reading. Cognitive Psychology, 6(2), 293-323. https://doi.org/10.1016/00100285(74)90015-2

Metcalfe, B. (2013). Metcalfe's law after 40 years of ethernet. Computer, 46(12), 26-31. https://doi.org/10.1109/MC.2013.374

National Academies of Sciences, Engineering, and Medicine. (2018). How people learn II: Learners, contexts, and cultures. National Academies Press. 
National Research Council (2000). How people learn (Vol. 11). National academy press.

Nolen, S. B., Horn, I. S., \& Ward, C. J. (2015). Situating motivation. Educational Psychologist, 50(3), 234-247. https://doi.org/10.1080/00461520.2015.1075399

Norton, B. (2013). Identity and language learning: Extending the conversation. Multilingual Matters. https://doi.org/10.21832/9781783090563

Norton, B. (2016). Identity and language learning: Back to the future. TESOL quarterly, 50(2), 475-479. https://doi.org/10.1002/tesq.293

Pellegrino, J. W., Chudowsky, N., \& Glaser, R. (2001). Knowing what students know: The science and design of educational assessment. National Academy Press.

Ryan, R. M., \& Deci, E. L. (2000). Self-determination theory and the facilitation of intrinsic motivation, social development, and well-being. American psychologist, 55(1), 68-78. https://doi.org/10.1037/0003-066X.55.1.68

Schraw, G., \& Olafson, L. (2003). Teachers' epistemological world views and educational practices. Journal of cognitive education and psychology, 3(2), 178-235. https://doi.org/10.1891/194589503787383109

Sfard, A. (1998). On two metaphors for learning and the dangers of choosing just one. Educational Researcher, 27(2), 4-13. https://doi.org/10.3102/0013189X027002004

Sinatra, G. M., Heddy, B. C., \& Lombardi, D. (2015). The challenges of defining and measuring student engagement in science. Educational Psychologist, 50(1), 1-13. https://doi.org/10.1080/00461520.2014.1002924

Soleimani, N. (2020). ELT teachers' epistemological beliefs and dominant teaching style: a mixed method research. Asian-Pacific Journal of Second and Foreign Language Education, 5(1), 1-20. https://sfleducation.springeropen.com/articles/10.1186/s40862020-00094-y

Vansteenkiste, M., Lens, W., Elliot, A. J., Soenens, B., \& Mouratidis, A. (2014). Moving the achievement goal approach one step forward: Toward a systematic examination of the autonomous and controlled reasons underlying achievement goals. Educational Psychologist, 49(3), 153-174. https://doi.org/10.1080/00461520.2014.928598

Vygotsky, L. (1978). Interaction between learning and development. Readings on the development of children, 23(3), 34-41.

Wagner, J. (2015). Designing for language learning in the wild: Creating social infrastructures for second language learning. Usage-based perspectives on second language learning, 75- 102.

Wenger, E. (1999). Communities of practice: Learning, meaning, and identity. Cambridge University Press. https://doi.org/10.1017/CBO9780511803932

Wigfield, A., \& Eccles, J. S. (2000). Expectancy-value theory of achievement motivation. $\begin{array}{lll}\text { Contemporary educational } & \text { psychology, }\end{array}$ https://psycnet.apa.org/doi/10.1006/ceps.1999.1015

Wiggins, G. (1998). Educative Assessment. Designing Assessments to Inform and Improve Student Performance. Jossey-Bass Publishers. 